\title{
The effects of gender and COMT Val158Met polymorphism on fearful facial affect recognition: a fMRI study
}

\author{
Matthew J. Kempton ${ }^{1,2}$, Morgan Haldane ${ }^{1}$, Jigar Jogia ${ }^{1}$, Tessa Christodoulou ${ }^{1}$, John Powell ${ }^{3}$, \\ David Collier ${ }^{4}$, Steven C. R. Williams ${ }^{2}$ and Sophia Frangou ${ }^{1}$ \\ ${ }^{1}$ Section of Neurobiology of Psychosis; ${ }^{2}$ Centre for Neuroimaging Sciences; ${ }^{3}$ MRC Centre for Neurodegeneration Research, \\ Department of Neuroscience; ${ }^{4}$ Social, Genetic and Developmental Psychiatry Research Centre, Institute of Psychiatry and NIHR \\ Biomedical Research Centre for Mental Health, King's College London, UK
}

\begin{abstract}
The functional catechol-O-methyltransferase (COMT Val108/158Met) polymorphism has been shown to have an impact on tasks of executive function, memory and attention and recently, tasks with an affective component. As oestrogen reduces COMT activity, we focused on the interaction between gender and COMT genotype on brain activations during an affective processing task. We used functional MRI (fMRI) to record brain activations from 74 healthy subjects who engaged in a facial affect recognition task; subjects viewed and identified fearful compared to neutral faces. There was no main effect of the COMT polymorphism, gender or genotype $\times$ gender interaction on task performance. We found a significant effect of gender on brain activations in the left amygdala and right temporal pole, where females demonstrated increased activations over males. Within these regions, Val/Val carriers showed greater signal magnitude compared to Met/Met carriers, particularly in females. The COMT Val108/158Met polymorphism impacts on gender-related patterns of activation in limbic and paralimbic regions but the functional significance of any oestrogen-related COMT inhibition appears modest.
\end{abstract}

Received 18 March 2008; Reviewed 25 April 2008; Revised 29 July 2008; Accepted 5 August 2008

Key words: Amygdala, COMT, fear, fMRI, gender.

\section{Introduction}

Catechol-O-methyltransferase (COMT) is involved in the degradation of catecholamine neurotransmitters. The gene that codes for the COMT enzyme contains a functional single nucleotide polymorphism at codon 158 with a valine (Val) substitution to methionine (Met) (Val158Met). The substitution of Val for Met is responsible for decreased enzymatic activity (Lotta et al., 1995) with Met homozygotes showing approximately one third less than Val158 homozygotes (Lachman et al., 1996). COMT provides the main mechanism for the degradation of released cortical dopamine (DA) (Gogos et al., 1998; Karoum et al., 1994a,b) and the Val158Met polymorphism

Address for correspondence: Professor S. Frangou, Section of Neurobiology of Psychosis (PO 66), Institute of Psychiatry, King's College London, De Crespigny Park, London SE5 8AF, UK. Tel.: + 442078480903 Fax: +442078480983

E-mail: s.frangou@iop.kcl.ac.uk seems to lead to significant variations in cognitive function.

Egan et al. (2001) were the first to report an association between the low-activity Met allele with fewer perseverative errors in the Wisconsin Card Sorting Test (WCST) and a more efficient task-related pattern of activation in the prefrontal cortex (PFC) in healthy participants. This lead Egan et al. to suggest that in the PFC, the COMT Val158 allele contributed to reduced DA signalling and neuronal signal-to-noise ratio. Since then, the effect of allelic variation of the COMT gene on cognitive function in healthy individuals has been extensively examined; here were report on findings pertaining to healthy individuals only from studies where they were either the main focus of the investigation or provided a control group for patient samples. The association between the low-activity Met allele and enhanced PFC efficiency in healthy participants has been replicated (Malhotra et al., 2002) and expanded to include the domains of working memory 
(Bertolino et al., 2006a; Mattay et al., 2003); encoding and retrieval (Bertolino et al., 2006b; Schott et al., 2006); and attention (Blasi et al., 2005). However, there have been studies reporting no effect of the COMT genotype in healthy individuals (Goldberg et al., 2003; Joober et al., 2002).

Currently the focus is on the effects of COMT polymorphism on emotional processing based on its reported association with personality traits such as the Met/Met genotype association with increased harm avoidance (Enoch et al., 2003), neuroticism among females (Eley et al., 2003) and outward acting aggression (Rujescu et al., 2003). There is also an association of COMT genotype with panic disorder (Domschke et al., 2004; Hamilton et al., 2002; Woo et al., 2002, 2004) and less so with depression (Massat et al., 2005; Ohara et al., 1998).

Two recent functional magnetic resonance imaging (fMRI) studies of healthy adults found an association between the number of Met alleles and increased activation in the amygdala/hippocampus complex in response to unpleasant pictures (Smolka et al., 2005) and in the right hippocampus and ventrolateral PFC when subjects viewed angry and fearful faces compared to geometric shapes (Drabant et al., 2006). This association between the number of Met alleles and increased limbic activation has been interpreted as evidence of reduced emotional resilience conferred by the Met allele.

COMT activity is significantly lower in females than males (Boudikova et al., 1990; Fahndrich et al., 1980; Floderus et al., 1981), a finding attributed to the inhibitory effect of oestrogen on COMT gene transcription (Jiang et al., 2003; Xie et al., 1999). It is thought that this sexually dimorphic effect of COMT Val/Met polymorphism on catecholamine metabolism may mediate, at least in part, the increased prevalence of anxiety and depression in females (Kessler et al., 1993, 1994; Weissman and Klerman, 1977). Indeed several studies have found panic disorder to be associated with the Val158Met polymorphism only in females (Domschke et al., 2004; Woo et al., 2004).

However, the behavioural expression of the interaction between gender and COMT appears complex. Studies examining single-sex samples have not found any effect of COMT Val158Met genotype on working memory or sustained attention in males (Smyrnis et al., 2007) or on perseverative errors in females (Tsai et al., 2003). Enoch et al. (2003) and Stein et al. (2005) found an effect of Val158Met polymorphism on harm avoidance and on the combination of low extraversion and high neuroticism only in females whilst Jabbi et al. (2007) found stress responses to be greater in male compared to female Met homozygotes.

This study focuses specifically on the interaction between the COMT Val/Met polymorphism and gender on patterns of brain activation during fMRI in healthy participants whilst performing a fearful facial affect recognition task. Fearful faces were chosen for two reasons. First, most of the evidence for an effect of the COMT Val/Met polymorphism relate to anxiety traits or disorders where there is heightened responsivity to threat-related cues (Beck and Clark, 1997; Mathews, 1998).

Second, males are less accurate and sensitive than females in labelling facial expressions but there is no gender difference in processing fearful expressions (Montagne et al., 2005) thus reducing potential confounders due to performance. Processing of fearful facial affect engages a widespread neural network with the most consistently found regions being the amygdala as well as the orbitofrontal and anterior cingulate cortices (Murphy et al., 2003; Phan et al., 2002).

Given the evidence for lower COMT activity in females and the risk of reduced emotional resilience conferred by the COMT 158Met allele we hypothesized that females homozygotes for the Met allele, would have the lowest enzyme activity and putatively higher DA concentrations and would therefore show amplified task-induced activations within limbic regions. These predictions are based specifically on the effect of the COMT genotype on the limbic system without fully accounting for the interaction of prefrontal and amygdala networks (Bilder et al., 2004). The effect of the COMT genotype is pronounced within the PFC with the Met allele being associated with increased cognitive control. It is therefore possible that a genotype-associated prefrontal-associated mechanism can override the effect of the genotype within the limbic regions.

\section{Materials and methods}

\section{Subjects}

Seventy-four healthy adults took part in this study (Table 1). Participants were recruited by advert and were included if they (a) were aged 18-65 yr, (b) had no personal lifetime history of mental health problems, substance use, head injury or medical disorders, (c) did not take any prescribed medication, (d) were of self-reported British white ancestry, (e) had no metallic objects in their body. 
Table 1. Demographic information and task performance

\begin{tabular}{|c|c|c|c|c|}
\hline & $\begin{array}{l}\text { Met/Met } \\
(n=20)\end{array}$ & $\begin{array}{l}\text { Met/Val } \\
(n=32)\end{array}$ & $\begin{array}{l}\text { Val/Val } \\
(n=22)\end{array}$ & Statistic \\
\hline Age (yr) & $34.6(15.6)$ & $35.7(12.5)$ & $33.9(13.7)$ & $F_{2,71}=0.12, p=0.88$ \\
\hline Gender (M:F) & $11: 9$ & $18: 14$ & $11: 11$ & $\chi_{(2)}^{2}=0.22, p=0.90$ \\
\hline Educational level & $3.4(0.9)$ & $3.7(0.9)$ & $3.5(1.0)$ & $F_{2,71}=0.94, p=0.39$ \\
\hline WAIS-R IQ & $115.1(20.1)$ & $119.0(14.7)$ & $117.6(20.3)$ & $F_{2,61}=0.24, p=0.79$ \\
\hline $\begin{array}{l}\text { Correctly identified } \\
\text { faces }(\%)\end{array}$ & $96.0(6.3)$ & $97.1(5.0)$ & $97.3(4.5)$ & $F_{2,71}=0.37, p=0.69$ \\
\hline Response time (ms) & $1050(166)$ & $1013(165)$ & $1116(258)$ & $F_{2,71}=1.8, p=0.18$ \\
\hline
\end{tabular}

WAIS-R, Wechsler Adult Intelligence Scale - Revised.

Data are expressed as mean (S.D.).

For WAIS-R IQ: $n=16$ for Met/Met, $n=28$ for Met/Val, $n=20$ for Val/Val.

\section{Assessment}

Participants were screened for the absence of any Axis I or Axis II diagnoses according to DSM-IV criteria (APA, 1994) following personal interview by trained psychiatrists using Structured Clinical Interview for DSM-IV (non-patient version) (First et al., 2002) and the SCID-II Personality Questionnaire for Axis II diagnoses (First et al., 1997).

An estimate of current intellectual function (IQ) was obtained using a shortened version of the Wechsler Adult Intelligence Scale - Revised (WAIS-R; Wechsler, 1981). Educational level was scored on a 5-point scale, where 1 indicated no formal qualifications and 5 indicated postgraduate-level qualifications.

The study was approved by the Ethics Committee of the Institute of Psychiatry and the South London and Maudsley NHS Trust. Written informed consent was obtained from all participants.

\section{DNA extraction and genotyping}

DNA was obtained from buccal swabs using established procedures (Freeman et al., 2003). The COMT Met/Val (rs4680) genotype was determined by a TaqMan Drug Metabolizing Genotyping assay (Applied Biosystems, Assay ID C_25746809_50) using the manufacturer's instructions. Endpoint analysis was performed on an ABI7900 DNA analyser and genotypes called with the SDS package with a probability $>95 \%$. To improve genotyping reliability sufficient additional samples of similar DNA quality and concentration were used to fill a complete plate for genotyping (382 samples and two controls).

\section{Fearful affect facial recognition task}

This comprised a 5-min, event-related task. Ten different facial identities (six female, four male; www. paulekman.com) depicting $150 \%$ intensity of a fearful expression were presented in a pseudo-random order interspersed with a fixation cross, and the same facial identities showing a neutral expression acted as a control condition. The $150 \%$ level of intensity was chosen to minimize ambiguity and uncertainty about the nature of the stimuli. In addition as noted by Phillips et al. (1997) images showing facial affect at $150 \%$ are recognized faster than images showing $75 \%$ and $100 \%$ of facial affect regardless of the actual nature of the affect (Calder et al., 1997).

Each image was displayed for $2 \mathrm{~s}$ and the interstimulus interval followed a Poisson distribution and was varied between $3 \mathrm{~s}$ and $9 \mathrm{~s}$ (mean interval $5 \mathrm{~s}$ ). In all 60 images were displayed; the fixation cross, faces with neutral expression, and faces expressing fear were each displayed 20 times. Participants were instructed to respond to fearful faces and faces with neutral expression by pressing the right and left button respectively on a MRI-compatible response box. No response was required when subjects viewed the fixation cross. Response time and accuracy data were collected.

\section{Image acquisition}

Gradient echo planar MR images were acquired using a $1.5 \mathrm{~T}$ GE Sigma MR system (General Electric, Milwaukee, WI, USA) fitted with $40 \mathrm{mT} / \mathrm{m}$ highspeed gradients. Foam padding and a forehead strap was used to limit head motion, and a quadrature birdcage head coil was used for radio frequency (RF) transmission and reception. In each of the 16 noncontiguous planes parallel to the inter-commissural (AC-PC) plane, $\mathrm{T}_{2}{ }^{*}$-weighted $\mathrm{MR}$ images depicting blood-oxygenation level-dependent (BOLD) contrast were acquired $(\mathrm{TR}=2000 \mathrm{~ms}, \mathrm{TE}=40 \mathrm{~ms}$, flip angle $=$ 
$70^{\circ}$, slice thickness $=7 \mathrm{~mm}$, slice skip $=0.7 \mathrm{~mm}$, matrix size $64 \times 64$, voxel dimensions $3.75 \times 3.75 \times 7.7 \mathrm{~mm}$ ). In the facial affect discrimination task 150 images were acquired. During the same session, a high-resolution $\mathrm{T}_{1}$ weighted structural image was acquired in the axial plane (inversion recovery prepared, spoiled gradient-echo sequence ; $\mathrm{TR}=18 \mathrm{~ms}, \mathrm{TE}=5.1 \mathrm{~ms}, \mathrm{TI}=$ $450 \mathrm{~ms}$, flip angle $=20^{\circ}$, slice thickness $=1.5 \mathrm{~mm}$, matrix size $256 \times 192$, FOV $240 \times 180 \mathrm{~mm}$, voxel dimensions $0.9375 \times 0.9375 \times 1.5 \mathrm{~mm}, \mathrm{NEX}=1$ ) for subsequent Talairach mapping (Talairach and Tourneaux, 1988).

\section{Image analysis}

Statistical analysis of the fMRI data was performed using SPM5 (Statistical Parametric Mapping, Wellcome Department of Imaging Neuroscience, London).

\section{Preprocessing}

Images were realigned to correct for movement and normalized into MNI space using the participant's structural MRI image. The transformed dataset for each subject was smoothed with an isotropic Gaussian filter (full width half maximum $=8 \mathrm{~mm}$ ) to compensate for normal variation in structural and functional anatomy across subjects.

\section{First level analysis}

Vectors of onset representing the correctly identified fearful faces and correctly identified neutral faces were convolved with the haemodynamic response function, global signal changes were removed and a high pass filter (128s) was applied to remove low-frequency artefacts for each subject. In the design matrix we also modelled the fixation cross, incorrect responses, and subject button response, although contrasts comparing these conditions were not used in the second level analysis. An explicit mask was used to ensure only voxels within the brain were included in the analysis. Six movement parameters were entered as nuisance covariates and contrast images of brain activations associated with correct recognition of fearful faces compared to neutral faces were produced for each participant.

\section{Second level analysis}

For the second level, random effects analysis, contrast images produced at the first level were used. First, a one-sample $t$ test was utilized combining all groups to investigate the main effect of task (correctly identified fearful faces $>$ correctly identified neutral faces). As the effect size of genotype and genotype $x$ gender interactions on brain activation is likely to be small and would not survive whole-brain correction for multiple comparisons, we used a region-of-interest (ROI) analysis, an approach adopted by other investigators (Drabant et al., 2006; Hariri et al., 2005; Smolka et al., 2005). As we were particularly interested in focusing on brain clusters modulated by gender we restricted our analysis to these specific areas.

These clusters were identified using an analysis of variance (ANOVA) model in SPM with gender as a factor. MarsBaR (Brett et al., 2002) was then used to extract measures of brain activation (weighted parameter estimates) from each subject at these particular clusters. Weighted parameter estimates were analysed using an ANOVA model within SPSS version 15.0 (SPSS Inc., Chicago, IL, USA) with gender and COMT genotype as factors. Partial eta squared $\left(\eta^{2}\right)$ was used as an estimate of effect size.

For the group task-related activation map a $p<0.05$ voxel-level, family-wise error (FWE) corrected threshold was used, and when investigating gender differences a $p<0.001$ voxel-level uncorrected threshold was employed based on the recommendations of Thirion et al. (2007) with a minimum cluster size of 25 voxels. In addition to the whole-brain analysis above we also examined activation in the amygdala which is consistently engaged by fearful stimuli as shown in fMRI meta-analyses (Murphy et al., 2003; Phan et al., 2002). The Wake Forest University Pickatlas was used to define the amygdala small-volume correction (http://www.fmri.wfubmc.edu/download. htm) (Maldjian et al., 2003) and activations were thresholded at the $p<0.05$ FWE-corrected level.

Supplementary MarsBaR analysis to investigate confounding effect of age and menstrual status

We undertook two additional analyses on activation levels of gender-modulated regions extracted with MarsBaR. As our sample included a relatively large age range, the MarsBaR analysis was repeated including age as a nuisance covariate. Oestrogen was not directly measured in this study. As a proxy marker we divided the female sample into two groups, one aged $\leqslant 35 \mathrm{yr}$ and the other $\geqslant 55 \mathrm{yr}$, the latter group assumed to be post-menopausal. We then compared the brain activation levels in the MarsBaR analysis between the two groups using an independent-sample $t$ test.

For all analyses, MNI coordinates produced by SPM were converted to Talairach coordinates (Duncan et al., 2000) and corresponding brain regions were identified 
with the Talairach Daemon Client (Lancaster et al., 2000).

Potential differences by genotype in age, gender, educational level and IQ were assessed using univariate ANOVAs or $\chi^{2}$ tests as appropriate within SPSS 15.0. Mean accuracy and mean response time to fearful faces were analysed using ANOVAs with genotype and gender as factors.

\section{Results}

There was no significant effect of genotype on age, gender, educational level, or IQ (see Table 1). Allele frequencies did not violate the Hardy-Weinberg principle among males $\left(\chi^{2}=0.4\right.$, d.f. $\left.=1, p=0.53\right)$, females $\left(\chi^{2}=1.02\right.$, d.f. $\left.=1, p=0.31\right)$, or in the entire sample $\left(\chi^{2}=1.34\right.$, d.f. $\left.=1, p=0.25\right)$. We found no significant effect of COMT allele, gender, or COMT allele $\times$ gender interaction on accuracy or response time in the task.

\section{Effect of task}

With all genotype groups combined, the fearful affect recognition task (fearful faces compared to neutral faces) activated regions in the left occipital gyrus [Brodmann area (BA) 18, Talairach coordinates $=-32$, $-88,-2 ; Z$ score $=7.15$, cluster size $=1172$ voxels], right lingual gyrus (BA 18, coordinates $=14,-82,-4$; $Z=6.50$, cluster size $=262$ ), right fusiform gyrus (BA 37 , coordinates $=40,-57,-14 ; Z=6.30$, cluster size $=$ $455)$ and left post-central gyrus (BA 40 , coordinates $=$ $-51,-32,51 ; Z=6.12$, cluster size $=1183$ ). For the small-volume-correction analysis of the amygdala, we observed bilateral activation of this region (left amygdala coordinates $=-22,-4,-16 ; Z=4.26$ cluster size $=127$; right amygdala coordinates $=20,-4,-20$; $Z=3.84$, cluster size $=58$ ).

\section{Effect of gender on task activations}

An effect of gender was observed on task-related activations in the left amygdala (Talairach coordinates $=-36,-3,-22 ; Z=3.72$, cluster size $=58$ voxels), in the region of the right temporal pole on the superior temporal gyrus (BA 38, coordinates $=50,16$, $-26 ; Z=3.46$, cluster size $=41)$, in the left superior occipital gyrus (BA 19, coordinates $=-42,-80,35$; $Z=3.86$, cluster size $=47)$ and the right precentral gyrus $(B A 4$, coordinates $=51,-10,39 ; Z=3.58$, cluster size $=76$ ). Females showed increased activation in the left amygdala, right temporal polar region and left superior occipital gyrus, while males demonstrated greater activations in the right precentral gyrus. The location of the clusters, and weighted parameter estimates for the left amygdala and right temporal pole are shown in Figure 1.

\section{Effect of genotype within clusters modulated by gender}

Within the left amygdala and right temporal polar region females demonstrated activations during the task, which were greater for female Val/Val than female Met/Met carriers. In contrast, males showed deactivation in both these regions with Met/Met carriers showing greater deactivation than Val/Val carriers. The left superior occipital gyrus revealed a different pattern with females showing little change from baseline and male Met/Met carriers showing greater deactivation than male $\mathrm{Val} / \mathrm{Val}$ carriers. In the right precentral gyrus deactivation was observed in females while males showed little change from baseline. For the left amygdala, brain activation values extracted using MarsBaR, revealed a main effect of gender $\left(F_{1,68}=20.2, p<0.001, \eta^{2}=0.23\right)$, main effect of genotype $\left(F_{2,68}=4.6, p=0.013, \eta^{2}=0.12\right)$ but no genotype $\times$ gender interaction $\left(F_{2,68}=0.64, p=0.53, \eta^{2}=0.02\right)$. For the right temporal pole, there was a main effect of gender $\left(F_{1,68}=18.4, p<.001, \eta^{2}=0.21\right)$ a trend for a main effect of genotype $\left(F_{2,68}=2.8, p=0.069, \eta^{2}=0.08\right)$ and a genotype $\times$ gender interaction $\left(F_{2,68}=3.8, p=\right.$ $\left.0.028, \eta^{2}=0.10\right)$. For the left superior occipital gyrus there was a main effect of gender $\left(F_{1,68}=15.1, p<0.001\right.$, $\left.\eta^{2}=0.18\right)$, no main effect of genotype $\left(F_{2,68}=0.036\right.$, $\left.p=0.97, \eta^{2}<0.01\right)$ and no genotype $\times$ gender interaction $\left(F_{2,68}=1.27, p=0.29, \eta^{2}=0.04\right)$, and for the right precentral gyrus there was a main effect of gender $\left(F_{1,68}=14.0, \quad p<0.001, \eta^{2}=0.17\right)$ no main effect of genotype $\left(F_{2,68}=1.32, p=0.27, \eta^{2}=0.04\right)$ and no genotype $\times$ gender interaction $\left(F_{2,68}=1.80, p=0.17, \eta^{2}=\right.$ $0.05)$.

The results did not change when age was used as a nuisance covariate and there was no difference in brain activation within these regions between menopausal $(\leqslant 35 \mathrm{yr})$ and post-menopausal $(\geqslant 55 \mathrm{yr})$ females ( $p>0.2$ for all clusters).

In summary, during this fearful affect recognition paradigm, the level of the BOLD signal in regions showing a gender effect was further modulated by COMT genotype in the left amygdala while a genotype $\times$ gender interaction was observed in the right temporal polar region.

In terms of the cognitive paradigm our study most closely resembles that of Drabant et al. (2006). We therefore explored the effect of gender and genotype on the hippocampal and ventrolateral prefrontal 
(a)

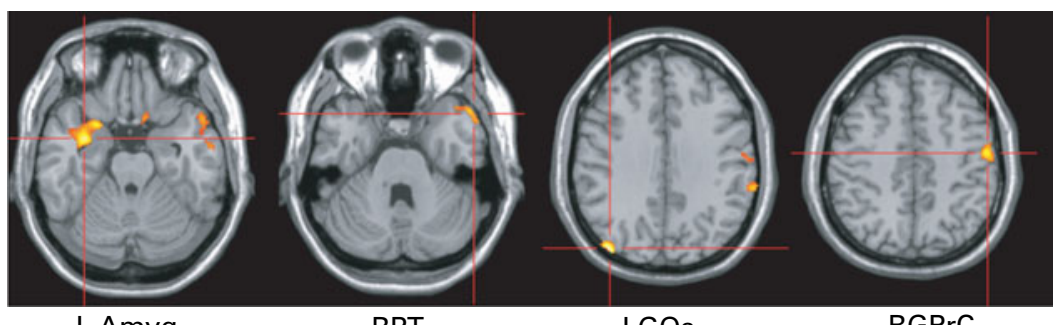

L Amyg

RPT

LGOs

RGPrC

(b)

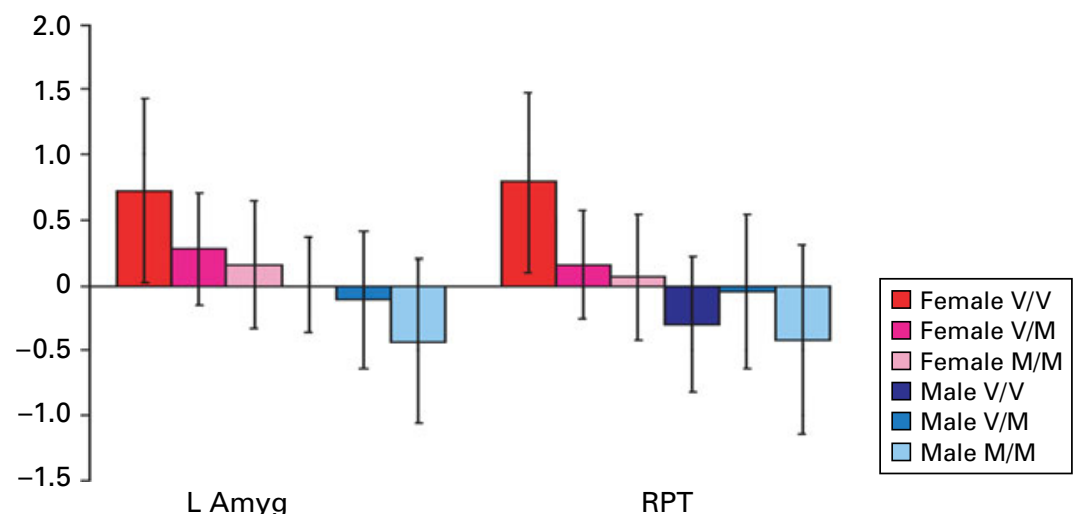

Figure 1. (a) Main effect of gender on brain activations during the fearful facial affect recognition task showing the four most significant clusters (images thresholded at $p<0.005$ uncorrected). (b) Brain activations for the left amygdala and right temporal pole divided by gender and genotype. L Amyg, Left amygdala; RPT, right temporal pole, LGOs, left superior occipital gyrus, RGPrC, right precentral gyrus.

cortical ROIs used by Drabant et al. based on the Wake Forest University Pickatlas. Small-volume-correction analysis showed no significant effect of genotype or genotype $\times$ gender interaction on brain activation in these regions (all $p>0.1$ corrected for ROI volume).

\section{Discussion}

During fearful facial affect recognition, differences in BOLD signal intensity, depending on gender were observed in left amygdala, right temporal polar region, left superior occipital gyrus and right precentral gyrus. Within these regions, an effect of genotype was seen for the left amygdala and a gender $\times$ genotype interaction was observed in the right temporal polar area.

\section{Main effect of gender}

We found that females showed increased task-related activation compared to males in the left amygdala whilst males appeared to inhibit neural response in this region.
In their meta-analysis of neuroimaging studies of emotional processing Wager et al. (2003) noted that amygdala involvement was generally more common on the left with gender differences in the distribution of peak activations. In females peak activations were more anterior and dorsal compared to males, often including the temporal pole and parahippocampal gyrus.

Engagement of the amygdala is reliably seen in fMRI studies of emotional facial affect recognition particularly in response to stimuli with negative affective content (Adolphs, 1999; Murphy et al., 2003). Amygdala activation is perhaps most consistently observed in response to passive or implicit viewing of fearful facial expressions (Phan et al., 2002). The predominance of left-lateralized amygdala activation during fearful facial affect recognition is thought to reflect the more rapid habituation of the right amygdala to repeated presentations of fearful stimuli (Wright et al., 2001). Amygdala responses are reduced when explicit labelling of the emotional expression is required (Critchley et al., 2000 ; Hariri et al., 2000) due to prefrontal inhibition. 
In the present study, deactivation of the left amygdala and the right temporal pole was observed in male but not in female participants. In addition to, and in agreement with our findings Koch et al. (2007) recently reported activation in the left amygdala of female participants, during a fMRI task that involved cognitive control of negative emotions, while males were successful in inhibiting amygdala response. Therefore our findings suggest that prefrontal inhibitory control of amygdala activation during negative emotional processing is more effective in males than in females.

Males also showed relative deactivation within the left superior occipital gyrus (BA 19), which was absent in females. BA 19 is part of the extrastriate visual cortex and primarily involved in early perceptual processing. Our results support current views that the amygdala modulates responses to emotional stimuli in visual cortices (Adolphs, 2002; Stein et al., 2007); and suggest that inhibitory feedback to the visual cortex by the amygdala is greater in males than females.

Engagement of the somatosensory cortex within the precentral gyri has often been observed in tasks involving assessment of facial affect and are interpreted as evidence of internal representation of somatic experiences associated with the observed emotional expressions (Adolphs, 2002). This study suggests that this emotional mimicry is perhaps minimal in males whereas in females there may be increased inhibition in this region.

\section{COMT Val158Met polymorphism and gender}

Our results suggest that Val homozygocity amplifies the magnitude of the BOLD signal in the amygdala and associated temporal polar regions in response to fearful faces. In the extrastriate visual and somatosensory cortices there was no significant effect of genotype or gender $\times$ genotype interaction.

Our results differ significantly from those of Drabant et al. (2006) who also examined the effect of the Val158Met polymorphism on facial affect recognition in healthy individuals. In their sample of $24 \mathrm{Met}$ and 20 Val homozygotes and 57 heterozygotes, they observed greater right hippocampal and right ventrolateral PFC (BA 45) activity in Met compared to Val homozygotes, but did not investigate the effect of gender. Similarly, an association between the number of Met alleles and increased activation in the amygdala/hippocampus complex in response to unpleasant pictures has also been reported (Smolka et al., 2005). It is possible that we were unable to detect a modulatory effect of COMT genotype within these brain regions because our sample was smaller, or because we did not control for other single nucleotide polymorphisms such as 5-HTTLPR genotype status which may modulate affective processing.

The paradigms in the above studies were based on passive viewing of negative facial expressions or aversive images while the one used in the present study required explicit labelling of facial expressions as neutral or fearful. Functional imaging studies have corroborated the notion that limbic responses are reduced when explicit labelling of an emotional expression is required due to prefrontal inhibition (Critchley et al., 2000; Hariri et al., 2000) and as already discussed this mechanism appears more effective in males regardless of COMT genotype.

Our results may be best explained by the model for the effect of the COMT Val158Met polymorphism on cognitive processing proposed by Bilder et al. (2004) based on the role of tonic and phasic DA release (Grace, 1991). According to this model, dynamic DA regulation within limbic regions results from two processes. First, high-amplitude transient, 'phasic' DA release occurs in response to relevant environmental stimuli and is mediated by dopaminergic neurone burst firing. Second, constant, low-level, 'tonic' DA concentration is regulated by baseline dopaminergic neurone firing and cortical afferents. Tonic DA levels regulate the amplitude of the phasic DA release by stimulating highly sensitive DA terminal autoreceptors. Phasic DA release acts at post-synaptic targets and is thought to be regulated by dopamine transporter (DAT) activity (Floresco et al., 2003; Grace, 1991, 1993; Moore et al., 1999); and not by COMT, given that it is not present in DA terminals (Gogos et al., 1998). Although COMT is expressed throughout the brain, Hong et al. (1998) have found the lowest expression evident in the amygdala whilst Revay et al. (1996) have provided evidence that amygdala DA catabolism is mainly mediated by the DAT. Within this framework, higher tonic DA concentration in the amygdala, putatively associated with the low-activity COMT Met158 allele, would reduce the amplitude of phasic DA release while the opposite would be the case for the COMT Val158 allele. At the same time, the presence of the COMT Met158 allele should be associated, at least in theory, with more efficient PFC function, and therefore improved inhibitory regulation in COMT Met allele carriers.

In line with the above model, female COMT Val158 homozygotes had the largest amygdala activation, which may be interpreted as indicative of greater 'phasic' response to fearful vs. neutral faces. Female 
COMT Met158 homozygotes showed smaller amygdala response which may reflect the inhibitory effects of higher tonic DA levels on phasic release and perhaps more efficient PFC regulation. The pattern seen in males is also suggestive of a more effective deactivation of the amygdala associated with the COMT Met158 allele. The proposed inhibitory effect of oestrogen on COMT activity was modest and only reached significance for the right temporal polar region.

We did not examine potential gender $\times$ genotype interactions on regional brain volumes but this is unlikely to have influenced our results since Zinkstok et al. (2006) found no such interaction in a sample of 154 healthy controls. We also did not control for menstrual cycle in female participants which may affect central DA neurotransmission. In healthy females positron emission tomography (PET) studies suggest reduced DA receptor density in the striatum during the luteal phase while prememopausal females with Parkinson's disease show symptomatic worsening also during the luteal phase which coincides with lower oestrogen levels, (Munro et al., 2006; Quinn and Marsden, 1986; Wong et al., 1988). However, no differences in regional brain activations were found when we compared females aged $\leqslant 35 \mathrm{yr}$ to females $\geqslant 55 \mathrm{yr}$, the latter presumed to be post-menopausal. Finally, other genetic (or even non-genetic) influences may impact on task-induced limbic activation during fearful facial affect recognition. Two obvious examples are the DAT gene, which is largely responsible for DA catabolism in the amygdala, and the regulatory region (5-HTTLPR) of the serotonin transporter gene, which is known to interact with the COMT Val158Met polymorphism (Smolka et al., 2007) during affective information processing. Although representative of the adult population, the age range in our sample was relatively large but the results remained unchanged when we included age as a nuisance covariate.

In summary this study provides evidence for an effect of the COMT Val158Met polymorphism on taskinduced limbic activation during fearful affect recognition with the Val allele being associated with amplified limbic response particularly in females.

\section{Acknowledgements}

None.

\section{Statement of Interest}

None.

\section{References}

Adolphs R (1999). The human amygdala and emotion. Neuroscientist 5, 125-137.

Adolphs R (2002). Recognizing emotion from facial expressions: psychological and neurological mechanisms. Behavioral and Cognitive Neuroscience Reviews 1, 21-62.

APA (1994). Diagnostic and Statistical Manual of Mental Disorders (DSM-IV). Washington, DC: American Psychiatric Association.

Beck AT, Clark DA (1997). An information processing model of anxiety: automatic and strategic processes. Behaviour Research and Therapy 35, 49-58.

Bertolino A, Blasi G, Latorre V, Rubino V, Rampino A, Sinibaldi L, Caforio G, Petruzzella V, Pizzuti A, Scarabino T, et al. (2006a). Additive effects of genetic variation in dopamine regulating genes on working memory cortical activity in human brain. Journal of Neuroscience 26, 3918-3922.

Bertolino A, Rubino V, Sambataro F, Blasi G, Latorre V, Fazio L, Caforio G, Petruzzella V, Kolachana B, Hariri A, et al. (2006b). Prefrontal-hippocampal coupling during memory processing is modulated by COMT val158met genotype. Biological Psychiatry 60, 1250-1258.

Bilder RM, Volavka J, Lachman HM, Grace AA (2004). The catechol-O-methyltransferase polymorphism: relations to the tonic-phasic dopamine hypothesis and neuropsychiatric phenotypes. Neuropsychopharmacology 29, 1943-1961.

Blasi G, Mattay VS, Bertolino A, Elvevag B, Callicott JH, Das S, Kolachana BS, Egan MF, Goldberg TE, Weinberger DR (2005). Effect of catechol-Omethyltransferase val158met genotype on attentional control. Journal of Neuroscience 25, 5038-5045.

Boudikova B, Szumlanski C, Maidak B, Weinshilboum R (1990). Human liver catechol-O-methyltransferase pharmacogenetics. Clinical Pharmacology \& Therapeutics 48, 381-389.

Brett M, Anton J, Valabregue R, Poline JB (2002). Region of interest analysis using an SPM toolbox [Abstract]. Presented at the 8th International Conferance on Functional Mapping of the Human Brain, 2-6 June 2002, Sendai, Japan. Available on CD-ROM in NeuroImage, vol 16, no. 2, abstract 497.

Calder AJ, Young AW, Rowland D, Perrett DI (1997). Computer-enhanced emotion in facial expressions. Proceedings of the Royal Society of London, Series B: Biological Sciences 264, 919-925.

Critchley H, Daly E, Phillips M, Brammer M, Bullmore E, Williams S, Van Amelsvoort T, Robertson D, David A, Murphy D (2000). Explicit and implicit neural mechanisms for processing of social information from facial expressions: a functional magnetic resonance imaging study. Human Brain Mapping 9, 93-105.

Domschke K, Freitag CM, Kuhlenbaumer G, Schirmacher A, Sand P, Nyhuis P, Jacob C, Fritze J, Franke P, Rietschel M, et al. (2004). Association of the functional V158M catechol-O-methyl-transferase polymorphism 
with panic disorder in women. International Journal of Neuropsychopharmacology 7, 183-188.

Drabant EM, Hariri AR, Meyer-Lindenberg A, Munoz KE, Mattay VS, Kolachana BS, Egan MF, Weinberger DR (2006). Catechol O-methyltransferase val158met genotype and neural mechanisms related to affective arousal and regulation. Archives of General Psychiatry 63, 1396-1406.

Duncan J, Seitz RJ, Kolodny J, Bor D, Herzog H, Ahmed A, Newell FN, Emslie H (2000). A neural basis for general intelligence. Science 289, 457-460.

Egan MF, Goldberg TE, Kolachana BS, Callicott JH, Mazzanti CM, Straub RE, Goldman D, Weinberger DR (2001). Effect of COMT Val108/158 Met genotype on frontal lobe function and risk for schizophrenia. Proceedings of the National Academy of Sciences USA 98, 6917-6922.

Eley TC, Tahir E, Angleitner A, Harriss K, McClay J, Plomin R, Riemann R, Spinath F, Craig I (2003). Association analysis of MAOA and COMT with neuroticism assessed by peers. American Journal of Medical Genetics, Part B: Neuropsychiatric Genetics 120, 90-96.

Enoch MA, Xu K, Ferro E, Harris CR, Goldman D (2003). Genetic origins of anxiety in women: a role for a functional catechol-O-methyltransferase polymorphism. Psychiatric Genetics 13, 33-41.

Fahndrich E, Coper H, Christ W, Helmchen H, MullerOerlinghausen B, Pietzcker A (1980). Erythrocyte COMT-activity in patients with affective disorders. Acta Psychiatrica Scandinavica 61, 427-437.

First MB, Spitzer RL, Gibbon M, Williams JBW (1997). Interview for DSM-IV Personality Disorders, (SCID-II). Washington, DC: American Psychiatric Press, Inc.

First MB, Spitzer RL, Gibbon M, Williams JBW (2002). Structured Clinical Interview for DSM-IV-TR Axis I Disorders Research Version Non-patient Edition (SCID-I/NP). New York: Biometrics Research, New York State Psychiatric Institute.

Floderus Y, Ross SB, Wetterberg L (1981). Erythrocyte catechol-O-methyltransferase activity in a Swedish population. Clinical Genetics 19, 389-392.

Floresco SB, West AR, Ash B, Moore H, Grace AA (2003). Afferent modulation of dopamine neuron firing differentially regulates tonic and phasic dopamine transmission. Nature Neuroscience 6, 968-973.

Freeman B, Smith N, Curtis C, Huckett L, Mill J, Craig IW (2003). DNA from buccal swabs recruited by mail: evaluation of storage effects on long-term stability and suitability for multiplex polymerase chain reaction genotyping. Behavioural Genetics 33, 67-72.

Gogos JA, Morgan M, Luine V, Santha M, Ogawa S, Pfaff D, Karayiorgou M (1998). Catechol-O-methyltransferasedeficient mice exhibit sexually dimorphic changes in catecholamine levels and behavior. Proceedings of the National Academy of Sciences USA 95, 9991-9996.

Goldberg TE, Egan MF, Gscheidle T, Coppola R, Weickert T, Kolachana BS, Goldman D, Weinberger DR (2003). Executive subprocesses in working memory: relationship to catechol-O-methyltransferase Val158Met genotype and schizophrenia. Archives of General Psychiatry 60, 889-896.

Grace AA (1991). Phasic versus tonic dopamine release and the modulation of dopamine system responsivity: a hypothesis for the etiology of schizophrenia.

Neuroscience 41, 1-24.

Grace AA (1993). Cortical regulation of subcortical dopamine systems and its possible relevance to schizophrenia. Journal of Neural Transmission (General Section) 91, 111-134.

Hamilton SP, Slager SL, Heiman GA, Deng Z, Haghighi F, Klein DF, Hodge SE, Weissman MM, Fyer AJ, Knowles JA (2002). Evidence for a susceptibility locus for panic disorder near the catechol-O-methyltransferase gene on chromosome 22, Biological Psychiatry 51, 591-601.

Hariri AR, Bookheimer SY, Mazziotta JC (2000). Modulating emotional responses: effects of a neocortical network on the limbic system. Neuroreport 11, 43-48.

Hariri AR, Drabant EM, Munoz KE, Kolachana BS, Mattay VS, Egan MF, Weinberger DR (2005). A susceptibility gene for affective disorders and the response of the human amygdala. Archives of General Psychiatry 62, 146-152.

Hong J, Shu-Leong H, Tao X, Lap-Ping Y (1998). Distribution of catechol-O-methyltransferase expression in human central nervous system. Neuroreport 9, 2861-2864.

Jabbi M, Kema IP, van der Pompe G, te Meerman GJ, Ormel J, den Boer JA (2007). Catechol-o-methyltransferase polymorphism and susceptibility to major depressive disorder modulates psychological stress response. Psychiatric Genetics 17, 183-193.

Jiang H, Xie T, Ramsden DB, Ho SL (2003). Human catechol-O-methyltransferase down-regulation by estradiol. Neuropharmacology 45, 1011-1018.

Joober R, Gauthier J, Lal S, Bloom D, Lalonde P, Rouleau G, Benkelfat C, Labelle A (2002). Catechol-Omethyltransferase Val-108/158-Met gene variants associated with performance on the Wisconsin Card Sorting Test. Archives of General Psychiatry 59, 662-663.

Karoum F, Chrapusta SJ, Brinjak R, Hitri A, Wyatt RJ (1994a). Regional effects of amphetamine, cocaine, nomifensine and GBR 12909 on the dynamics of dopamine release and metabolism in the rat brain. British Journal of Pharmacology 113, 1391-1399.

Karoum F, Chrapusta SJ, Egan MF (1994b). 3-Methoxytyramine is the major metabolite of released dopamine in the rat frontal cortex: reassessment of the effects of antipsychotics on the dynamics of dopamine release and metabolism in the frontal cortex, nucleus accumbens, and striatum by a simple two pool model. Journal of Neurochemistry 63, 972-979.

Kessler RC, McGonagle KA, Swartz M, Blazer DG, Nelson CB (1993). Sex and depression in the National Comorbidity Survey. I: Lifetime prevalence, chronicity and recurrence. Journal of Affective Disorders 29, 85-96.

Kessler RC, McGonagle KA, Zhao S, Nelson CB, Hughes M, Eshleman S, Wittchen HU, Kendler KS (1994). Lifetime and 12-month prevalence of DSM-III-R psychiatric disorders in the United States. Results from the National Comorbidity Survey. Archives of General Psychiatry 51, 8-19. 
Koch K, Pauly K, Kellermann T, Seiferth NY, Reske M, Backes V, Stocker T, Shah NJ, Amunts K, Kircher T, et al. (2007). Gender differences in the cognitive control of emotion: an fMRI study. Neuropsychologia 45, 2744-2754.

Lachman HM, Papolos DF, Saito T, Yu YM, Szumlanski CL, Weinshilboum RM (1996). Human catechol-Omethyltransferase pharmacogenetics: description of a functional polymorphism and its potential application to neuropsychiatric disorders. Pharmacogenetics 6, 243-250.

Lancaster JL, Woldorff MG, Parsons LM, Liotti M, Freitas CS, Rainey L, Kochunov PV, Nickerson D, Mikiten SA, Fox PT (2000). Automated Talairach atlas labels for functional brain mapping. Human Brain Mapping 10, 120-131.

Lotta T, Vidgren J, Tilgmann C, Ulmanen I, Melen K, Julkunen I, Taskinen J (1995). Kinetics of human soluble and membrane-bound catechol O-methyltransferase: a revised mechanism and description of the thermolabile variant of the enzyme. Biochemistry 34, 4202-4210.

Maldjian JA, Laurienti PJ, Kraft RA, Burdette JH (2003). An automated method for neuroanatomic and cytoarchitectonic atlas-based interrogation of fMRI data sets. Neuroimage 19, 1233-1239.

Malhotra AK, Kestler LJ, Mazzanti C, Bates JA, Goldberg T, Goldman D (2002). A functional polymorphism in the COMT gene and performance on a test of prefrontal cognition. American Journal of Psychiatry 159, 652-654.

Massat I, Souery D, Del-Favero J, Nothen M, Blackwood D, Muir W, Kaneva R, Serretti A, Lorenzi C, Rietschel M, et al. (2005). Association between COMT (Val158Met) functional polymorphism and early onset in patients with major depressive disorder in a European multicenter genetic association study. Molecular Psychiatry 10, 598-605.

Mathews AMB (1998). A cognitive model of selective processing in anxiety. Cognitive Therapy and Research 22, 539-560.

Mattay VS, Goldberg TE, Fera F, Hariri AR, Tessitore A, Egan MF, Kolachana B, Callicott JH, Weinberger DR (2003). Catechol O-methyltransferase val158-met genotype and individual variation in the brain response to amphetamine. Proceedings of the National Academy of Sciences USA 100, 6186-6191.

Montagne B, Kessels RPC, Frigerio E, De Haan EHF, Perrett DI (2005). Sex differences in the perception of affective facial expressions: do men really lack emotional sensitivity? Cognitive Processing 6, 136-141.

Moore H, West AR, Grace AA (1999). The regulation of forebrain dopamine transmission: relevance to the pathophysiology and psychopathology of schizophrenia. Biological Psychiatry 46, 40-55.

Munro CA, McCaul ME, Wong DF, Oswald LM, Zhou Y, Brasic J, Kuwabara H, Kumar A, Alexander M, Ye W, Wand GS (2006). Sex differences in striatal dopamine release in healthy adults. Biological Psychiatry 59, 966-974

Murphy FC, Nimmo-Smith I, Lawrence AD (2003). Functional neuroanatomy of emotions: a meta-analysis. Cognitive, Affective, E Behavioral Neuroscience 3, 207-233.

Ohara K, Nagai M, Suzuki Y, Ohara K (1998). Low activity allele of catechol-o-methyltransferase gene and Japanese unipolar depression. Neuroreport 9, 1305-1308.

Phan KL, Wager T, Taylor SF, Liberzon I (2002). Functional neuroanatomy of emotion: a meta-analysis of emotion activation studies in PET and fMRI. Neuroimage 16, 331-348.

Phillips ML, Young AW, Senior C, Brammer M, Andrew C, Calder AJ, Bullmore ET, Perrett DI, Rowland D, Williams SC, et al. (1997). A specific neural substrate for perceiving facial expressions of disgust. Nature 389, 495-498.

Quinn NP, Marsden CD (1986). Menstrual-related fluctuations in Parkinson's disease. Movement Disorders 1, 85-87.

Revay R, Vaughan R, Grant S, Kuhar MJ (1996). Dopamine transporter immunohistochemistry in median eminence, amygdala, and other areas of the rat brain. Synapse 22, 93-99.

Rujescu D, Giegling I, Gietl A, Hartmann AM, Moller HJ (2003). A functional single nucleotide polymorphism $(\mathrm{V} 158 \mathrm{M})$ in the COMT gene is associated with aggressive personality traits. Biological Psychiatry 54, 34-39.

Schott BH, Seidenbecher CI, Fenker DB, Lauer CJ, Bunzeck N, Bernstein HG, Tischmeyer W, Gundelfinger ED, Heinze HJ, Duzel E (2006). The dopaminergic midbrain participates in human episodic memory formation: evidence from genetic imaging. Journal of Neuroscience 26, 1407-1417.

Smolka MN, Buhler M, Schumann G, Klein S, Hu XZ, Moayer M, Zimmer A, Wrase J, Flor H, Mann K, et al. (2007). Gene-gene effects on central processing of aversive stimuli. Molecular Psychiatry 12, 307-317.

Smolka MN, Schumann G, Wrase J, Grusser SM, Flor H, Mann K, Braus DF, Goldman D, Buchel C, Heinz A (2005). Catechol-O-methyltransferase val158met genotype affects processing of emotional stimuli in the amygdala and prefrontal cortex. Journal of Neuroscience $25,836-842$.

Smyrnis N, Avramopoulos D, Evdokimidis I, Stefanis CN, Tsekou H, Stefanis NC (2007). Effect of schizotypy on cognitive performance and its tuning by COMT val158 met genotype variations in a large population of young men. Biological Psychiatry 61, 845-853.

Stein JL, Wiedholz LM, Bassett DS, Weinberger DR, Zink CF, Mattay VS, Meyer-Lindenberg A (2007). A validated network of effective amygdala connectivity. Neuroimage 36, 736-745.

Stein MB, Fallin MD, Schork NJ, Gelernter J (2005). COMT polymorphisms and anxiety-related personality traits. Neuropsychopharmacology 30, 2092-2102.

Talairach J, Tourneaux P (1988). A Co-planar Stereotactic Atlas of a Human Brain. Stuttgart: Thieme.

Thirion B, Pinel P, Meriaux S, Roche A, Dehaene S, Poline JB (2007). Analysis of a large fMRI cohort: statistical and methodological issues for group analyses. Neuroimage 35, 105-120. 
Tsai SJ, Yu YW, Chen TJ, Chen JY, Liou YJ, Chen MC, Hong CJ (2003). Association study of a functional catechol-O-methyltransferase-gene polymorphism and cognitive function in healthy females. Neuroscience Letters 338, 123-126.

Wager TD, Phan KL, Liberzon I, Taylor SF (2003). Valence, gender, and lateralization of functional brain anatomy in emotion: a meta-analysis of findings from neuroimaging. Neuroimage 19, 513-531.

Wechsler D (1981). Wechsler Adult Intelligence Scale-Revised (WAIS-R) Manual. New York: Psychological Corporation.

Weissman MM, Klerman GL (1977). Sex differences and the epidemiology of depression. Archives of General Psychiatry 34, 98-111.

Wong DF, Broussolle EP, Wand G, Villemagne V, Dannals RF, Links JM, Zacur HA, Harris J, Naidu S, Braestrup C, et al. (1988). In vivo measurement of dopamine receptors in human brain by positron emission tomography. Age and sex differences. Annals of the New York Academy of Science 515, 203-214.
Woo JM, Yoon KS, Choi YH, Oh KS, Lee YS, Yu BH (2004). The association between panic disorder and the $\mathrm{L} / \mathrm{L}$ genotype of catechol-O-methyltransferase. Journal of Psychiatric Research 38, 365-370.

Woo JM, Yoon KS, Yu BH (2002). Catechol Omethyltransferase genetic polymorphism in panic disorder. American Journal of Psychiatry 159, 1785-1787.

Wright CI, Fischer H, Whalen PJ, McInerney SC, Shin LM, Rauch SL (2001). Differential prefrontal cortex and amygdala habituation to repeatedly presented emotional stimuli. Neuroreport 12, 379-383.

Xie T, Ho SL, Ramsden D (1999). Characterization and implications of estrogenic down-regulation of human catechol-O-methyltransferase gene transcription. Molecular Pharmacology 56, 31-38.

Zinkstok J, Schmitz N, van Amelsvoort T, de Win M, van den Brink W, Baas F, Linszen D (2006). The COMT val158met polymorphism and brain morphometry in healthy young adults. Neuroscience Letters 405, 34-39. 